\title{
HUBUNGAN DAYA TAHAN AEROBIK DAN DAYA TAHAN KEKUATAN OTOT LENGAN DENGAN KEMAMPUAN SMASH PEMAIN BULUTANGKIS
}

\author{
Arie Asnaldi ${ }^{1}$ \\ ${ }^{1}$ Fakultas Ilmu Keolahragaan, Universitaas Negeri Padang, Indoensia \\ asnaldi@ fik.unp.ac.id ${ }^{1}$
}

Info Artikel
Sejarah Artikel:

Diterima Mareti 2020

Disetujui April 2020

Dipublikasikan Juni 2020
Kata Kunci: Daya Tahan Aerobik, Kekuatan Otot Lengan, Smash Keywords: Aerobic Endurance, Muscle Strength Arm, Smash

\begin{abstract}
Abstrak
Penelitian ini berawal dari hasil observasi yang penulis temui di lapangan, di duga daya tahana erobik dan daya tahan kekuatan otot lengan memberikan hubungan terhadap kemampuan smash pemain bulutangkis perkumpulan bulutangkis Pasie Nan Tigo. Tujuan penelitian ini adalah untuk mengetahui hubungan daya tahana erobik dan daya tahan kekuatan otot lengan dengan kemampuan smash pemain bulutangkis. Jenis penelitian adalah korelasional, populasi adalah pemain bulutangkis perkumpulan bulutangkis Pasie Nan Tigo yang berjumlah 20 orang. Penarikan sampel yang digunakana dalah Total Sampling. Data diambil dengan tiga cara, (1) Multistage Fitness Test untuk mengukur dayatahan aerobik, (2)Pull Ups Chinnings Test untuk mengukur daya tahan kekuatan otot lengan dan (3) tes smash untuk mengukur kemampuan smash. Data yang diperoleh dianalisis dengan korelasi Product Moment sederhana dan ganda. Analisis dari pembahasan ini dapat disimpulkan bahwa 1) Terdapat hubungan yang signifikan antara daya tahan aerobik dengan kemampuan smash, dengan $\alpha(0,05) \mathrm{r}_{\text {hitung }}(0,6545)$ $\left.>r_{\text {tab }}(0,4560), 2\right)$ Terdapat hubungan yang signifikan antara daya tahan kekuatan otot lengan dengan kemampuan smash, dengan $\alpha(0,05) \mathrm{r}_{\text {hitung }}(0,5196)>\mathrm{r}_{\mathrm{tab}}$ $(0,4560), 3)$ Terdapat hubungan yang signifikan secara bersama-sama antara daya tahan aerobik dan daya tahan kekuatan otot lengan dengan kemampuan smash, dengan $\alpha(0,05) \mathrm{R}_{\text {hitung }}(0,7279)>\mathrm{R}_{\mathrm{tab}}(0,4560)$.
\end{abstract}

\section{Abstrack}

Research started from the observation that the authors encountered in the field, in the sense of erobic power and durability of the arm muscle strength gives a connection to the ability to smash the badminton Club badminton players Pasie Nan Tigo. The purpose of this research is to know the relationship of erobic endurance and the durability of arm muscle strength with badminton player's smash capability. The type of research is correlational, the population is a Pasie naan Tigo Badminton Club badminton player with a total of 20 people. Withdrawal of samples used in Total Sampling. Data is taken in three ways, (1) Multistage Fitness Test to measure aerobic power, (2) Pull Ups Chinnings Test to measure the durability of the arm muscle strength and (3) Smash test 
to measure the smash capability. Data obtained is analyzed with the correlation Product Moment simple and double. Analysis of this discussion can be concluded that 1) there is a significant relationship between aerobic endurance and smash ability, with $\alpha(0.05) R_{\text {count }}(0.6545)$ $>R_{\text {tab }}(0.4560)$, 2) There is a significant relationship between the endurance of the muscle strength of the arm with a smash capability, with $\alpha(0.05) R_{\text {countdown }}(0.5196)>$ $R_{\text {tab }}(0.4560)$, 3) There is a significant link together between the aerobic endurance and endurance muscles strength of the arm with the smash ability, with $\alpha(0.05)$ $R_{\text {count }}(0.7279)>R_{\text {tab }}(0.4560)$.

C 2020 Universitas Suryakancana

e-ISSN : 2721-7175(online) p-ISSN : 2089-2341 (cetak)

\section{PENDAHULUAN}

Meningkatkan keterampilan dalam bermain bulutangkis, pemain harus memiliki wadah yang bisa memberikan pengetahuan, pengalaman dan prestasi dalam bidang bulutangkis. Menurut (Zil Isra, 2020)

Di Sumatera Barat Kota Padang sangat banyak tempat latihan yang dapat memfasilitasi seorang pemain dan atau atlet agar mendapat pengetahuan dan ketrampilan. Karena menurut (Asnaldi, 2019) Olahraga adalah suatu aktivitas yang banyak dilakukan oleh masyarakat, keberadaannya sekarang ini tidak lagi dipandang sebelah mata tetapi sudah menjadi bagian dari kehidupan masyarakat."

Sedangkan karateriktik permainan ini menurut (Asnaldi, 2016) „Karakteristik permainan bulutangkis dimainkan oleh dua orang dan empat orang, dengan masingmasing terdiri dari pemain tunggal putraputri, pasangan ganda putra-putri dan pasangan ganda campuran. Permainan bulutangkis dimulai dengan penyajian bola atau servis dari salah seorang pemain kepada lawannya secara diagonal atau jalannya bola menyilang“"

Dalam permainan bulutungkis, pemain akan tampak menonjol di bandingkan dengan pemain lain jika menguasai teknik dasar bulutangkis, banyak contoh teknik dasar bulutangkis di antaranya servis, lob, coke dan smash, masing-masing teknik sangat dibutuhkan dalam permainan bulutangkis. Hal ini dipertegas lagi oleh perndapat (Asnaldi, 2016) bahwa " kemampuan teknik dasar yang masih belum dikuasai dengan baik seperti teknik pukulan smash, drive, dropshot, lob, servis, net play, olah kaki dan pola-pola pukulan sehingga pemain tidak bisa menampilkan permainan terbaiknya."

Salah satu teknik dasar yang penting dalam cabang bulutangkis adalah smash. Smash adalah teknik memukul bola dengan keras, 
tajam, dan menempatkannya pada posisi yang tepat. Hal dijelaskan (Asnaldi, 2020) Untuk dapat menghasilkan smash bola voli yang baik dibutuhkan kondisi fisik kelentukan dan daya ledak otot lengan yang prima dari pemain selain itu juga diharapkan kepada pelatih untuk mengembangkan model dan bentuk dari materi latihan yang diberikan“.

Jika pemain dapat menguasai teknik smash maka permainan akan tampak menarik, banyak pemain hebat di cabang bulutangkis yang dapat memukul tajam ke daerah sulit lawan. Penjelasan diatas senada dengan pendapat (Zil Isra, 2020) sebegai berikut:

\section{METODE}

Variabel Penelitian Variabel adalah objek penelitian yang menjadi titik pusat perhatian suatu penelitian. Penelitian korelasi

\section{Jenis penelitian}

Penelitian ini termasuk jenis penelitian korelasional. Jenis penelitian korelasional untuk melihat hubungan antara variabel bebas dan variabel terikat".

Hubungan yag dimaksud adalah hubungan fungsional yang didasarkan pada teori yang sudah ada dan logika berfikir yang dapat diterima, sehingga korelasi yang dimaksud bukan hanya menghubungkan dua data yang tidak memiliki makna, namun benarbenar didasari oleh teori tertentu.

\section{Populasi dan Sampel}

Dengan demikian populasi dalam penelitian ini adalah pemain bulutangkis Pasie Nan Tigo Kota Padang.

Tabel 1. Populasi Pasie Nan Tigo

\begin{tabular}{|c|c|c|c|}
\hline No & Tingkatan & $\begin{array}{c}\text { Kelompok } \\
\text { umur }\end{array}$ & Jumlah \\
\hline 1 & Dewasa & $\begin{array}{c}\text { Usia 19-25 } \\
\text { tahun }\end{array}$ & 20 \\
\hline \multicolumn{2}{|c|}{ Jumlah Total } & & 20 \\
\hline
\end{tabular}

Berhubung karena jumlah populasi dalam penelitian ini relatif sedikit, maka semua populasi dijadikan sampel (Erik Eriyaldi, 2019) Pengambilan sampel dilakukan secara total sampling yaitu adalah teknik pengambilan sampel dimana jumlah sampel sama dengan. Jadi teknik penarikan sampel yang digunakan adalah total sampling, sehingga sampel peneliti berjumlah 20 orang pemain

\section{Teknik Pengumpulan Data}

1. Daya tahan aerobik

Pada buku tes dan pengukuran olahraga oleh Ismaryati menjelaskan bahwa untuk mencari tau daya tahan aerobik atlit dengan mengunakan instrumen tes multistage fitnest.

2. Daya tahan kekuatan otot lengan

Untuk mengetahui daya tahan kekuatan otot lengan digunakan istrumen tes pull ups chinnings .

\section{Smash}

James poole menjelaskan, untuk mengukur ketepatan smash atlit dengan cara melakukan 10 kali smash ke daerah yang telah di persiakan. 


\section{HASIL dan PEMBAHASAN}

Berdasarkan penelitian yang dilakukansampel berjumlah 20 orang pemain. Sesuai dengan analisis korelasi Product Moment dan korelasi ganda, maka terdapat tiga unit analisis data dalam penelitian ini. Deskriptif data dari masingmasing unit analisis ini menunjukan hasil sebagai berikut:

\section{Daya Tahan Aerobik}

Pengukuran daya tahan aerobik dilakukan dengan Multistage Fitness Test terhadap 20 orang pemain, didapat hasil tertinggi 44,2, hasil terendah 30,6, rata-rata (mean) 37,64 , simpangan baku (standar deviasi) 4,11. Dari data hasil tes ini dapat dibuatkan tabel distribusi frekwensi sebagai berikut:

Tabel 3. Distribusi Frekwensi Variabel Daya Tahan Aerobik

\begin{tabular}{cccc}
\hline No & Kelas Interval & $\begin{array}{c}\text { Frekwensi } \\
\text { Absolute (FA) }\end{array}$ & $\begin{array}{c}\text { Frekwensi } \\
\text { Relative (FR) }\end{array}$ \\
\hline 1 & $30,6-33,6$ & 4 & 20 \\
2 & $33,7-36,7$ & 4 & 20 \\
3 & $36,8-39,8$ & 4 & 20 \\
4 & $39,9-42,9$ & 6 & 30 \\
5 & $42,0-45,0$ & 2 & 10 \\
& Jumlah & 20 & $100 \%$ \\
\hline
\end{tabular}

\section{Daya Tahan Kekuatan Otot Lengan}

Pengukuran daya tahan kekuatan otot lengan dilakukan dengan Pull Ups Chinnings Test terhadap 20 orang pemain, didapat nilai tertinggi 14 , niai terendah 4 , rata-rata (mean) 9,20, simpangan baku (standar deviasi) 2,54, dari data hasil tes ini dapat dibuatkan tabel distribusi frekwensi sebagai berikut:

\section{Tabel 4. Distribusi Frekwensi Variabel}

Daya Tahan Kekuatan Otot Lengan

\begin{tabular}{cccc}
\hline No & Kelas Interval & $\begin{array}{c}\text { Frekwensi } \\
\text { Absolute (FA) }\end{array}$ & $\begin{array}{c}\text { Frekwensi } \\
\text { Relative (FR) }\end{array}$ \\
\hline 1 & $4-6$ & 2 & 10 \\
2 & $7-9$ & 10 & 50 \\
3 & $10-12$ & 6 & 30 \\
4 & $13-15$ & 2 & 10 \\
& Jumlah & 20 & $100 \%$ \\
\hline
\end{tabular}

\section{Kemampuan Smash}

Pengukuran kemampuan Smash dilakukan dengan Smash Test terhadap 20 orang pemain, didapat skor tertinggi 28, skor terendah 12, rata-rata (mean)19,65, simpangan baku (standar deviasi) 4,60, dari data hasil tes ini dapat dibuatkan tabel distribusi frekwensi sebagai berikut:

Tabel 5. Distribusi Frekwensi Variabel Kemampuan Smash

\begin{tabular}{cccc}
\hline No & Kelas Interval & $\begin{array}{c}\text { Frekwensi } \\
\text { Absolute (FA) }\end{array}$ & $\begin{array}{c}\text { Frekwensi } \\
\text { Relative (FR) }\end{array}$ \\
\hline 1 & $12-15$ & 6 & 30 \\
2 & $16-19$ & 5 & 25 \\
3 & $20-23$ & 4 & 20 \\
4 & $24-27$ & 4 & 20 \\
5 & $28-31$ & 1 & 5 \\
& Jumlah & 20 & $100 \%$ \\
\hline
\end{tabular}

Berdasarkan pada tabel distribusi frekuensi di atas dari 20 pemain, terdapat 6 orang pemain (30\%) memiliki hasil kemampuan Smash dengan rentangan nilai 12-15, kemudian 5 orang pemain (25\%) memiliki hasil kemampuan Smash dengan rentangan nilai 16-19, lalu 4 orang pemain (20\%) memiliki hasil kemampuan Smash dengan rentangan nilai 20-23, sedangkan sebanyak 4 orang pemain (20\%) memiliki hasil kemampuan Smash dengan rentangan nilai 24-27, dan sisanya 1 orang pemain 5\%) memiliki hasil kemampuan Smash dengan rentangan nilai 28-31.

\section{B. Pengujian Persyaratan Analisis} dengan Uji Normalitas Data 
Analisis uji normalitas data dilakukan dengan uji Lilliefors. Hasil analisis uji normalitas masing-masing variabel disajikan dalam bentuk tabel di bawah ini.

Tabel 6. Uji Normalitas Data dengan Uji Lilliefors

\begin{tabular}{clccc}
\hline No & \multicolumn{1}{c}{ Variabel } & Lo & Lt & Keterangan \\
\hline 1 & Daya Tahan Aerobik & 0,1239 & 0,1900 & Normal \\
2 & Daya Tahan Kekuatan Otot Lengan & 0,0569 & 0,1900 & Normal \\
3 & Kemampuan Smash & 0,0938 & 0,1900 & Normal \\
\hline
\end{tabular}

Pada tabel di atas dapat dilihat bahwa hasil Lo variabel daya tahan aerobik, daya tahan kekuatan otot lengan dan kemampuan Smash lebih kecil dari Lt, maka dapat disimpulkan bahwa data berdistribusi normal.

\section{Pengujian Hipotesis}

\section{Uji Hipotesis Satu}

Pengujian hipotesis pertama yaitu terdapat hubungan antara daya tahan aerobik dengan kemampuan Smash. Berdasarkan analisis dilakukan, maka didapat rata-rata kemampuan Smash 19,65 dengan simpangan baku 4,60.

Untuk skor rata-rata daya tahan aerobik didapat 37,64 dengan simpangan baku 4,11. Dari keterangan di atas diperoleh analisis korelasi antara daya tahan aerobik dan kemampuan Smash, dimana $r_{\text {tab }}$ pada tarafsignifikan $\alpha(0,05)$ dan $\mathrm{db}=\mathrm{n}-1$, diperoleh nilai $\mathrm{r}_{\mathrm{tab}}=0,4560$ berarti $r_{\text {hitung }}(0,5622)>r_{\text {tab }}(0,4560)$, artinya hipotesis diterima dan terdapat hubungan yang berarti antara daya tahan aerobik dengan kemampuan Smash pemain bulutangkis Pasie Nan Tigo.

\author{
Uji keberartian koefisien korelasi \\ antara variabel $\mathrm{X}_{1}$ dengan $\mathrm{Y}$ Dengan $\alpha$ \\ $=0,05$ dan $\mathrm{db}=\mathrm{n}-1$, diperoleh nilai \\ $t_{\text {tabel }}=2,0930$. Kriteria pengujian adalah: \\ jika $t_{\text {hitung }}<t_{\text {tabel }}$ Ho diterima, Oleh \\ karena $t_{\text {hitung }}(2,8843)>t_{\text {tabel }}(2,0930)$ \\ maka Ho ditolak, dan Ha diterima.
}

Tabel 7. Analisis Korelasi antara Daya Tahan Aerobik terhadap Kemampuan Smash $\left(\mathbf{X}_{1}-\mathbf{Y}\right)$

\begin{tabular}{cccccc}
\hline db (N-1) & $\mathrm{r}_{\text {hitung }}$ & $\begin{array}{c}\mathrm{r}_{\text {tabel }} \\
\square=0,05\end{array}$ & thiung & $\begin{array}{c}\text { tabel } \\
\square=0,05\end{array}$ & Kesimpulan \\
\hline 19 & 0,5622 & 0,4560 & 2,8843 & 2,0930 & Signifikan \\
\hline
\end{tabular}

Hasil analisis korelasi menyatakan terdapat hubungan yang signifikan antara daya tahan aerobik dengan kemampuan Smash pada taraf signifikan $\alpha=0,05$.

\section{Uji Hipotesis Dua}

Berdasarkan analisis dilakukan, maka didapat rata-rata kemampuan Smash 19,65 dengan simpangan baku 4,60. Untuk skor rata-rata daya tahan kekuatan otot lengan didapat 9,20 dengan simpangan baku 2,54. Dari keterangan di atas diperoleh analisis korelasi antara daya tahan kekuatan otot lengan dengan kemampuan Smash, dimana $\mathrm{r}_{\text {tab }}$ pada taraf signifikan $\alpha(0,05)$ dan $\mathrm{db}=$ $\mathrm{n}-1, \quad$ diperoleh nilai $\mathrm{r}_{\mathrm{tab}}=0,4560$ $\mathrm{r}_{\text {hitung }}(0,5196)>\mathrm{r}_{\mathrm{tab}}(0,4560)$, artinya hipotesis diterima dan terdapat hubungan yang berarti antara daya tahan kekuatan otot lengan dengan kemampuan Smash pemain bulutangkis Pasie Nan Tigo. 
Uji keberartian koefisien korelasi antara variabel $X_{2}$ dengan $Y$ Dengan $\alpha=0,05$ dan $\mathrm{db}=\mathrm{n}-1$, diperoleh nilai $\mathrm{t}_{\text {tabel }}=2,0930$. Kriteria pengujian adalah: jika $t_{\text {hitung }}<t_{\text {tabel }}$ Ho diterima, Oleh karena $t_{\text {hitung }}(2,5799)>$ $t_{\text {tabel }}(2,0930)$ maka Ho ditolak, dan Haditerima.

Tabel 8. Analisis Korelasi antara Daya Tahan Kekuatan Otot Lengan terhadap Kemampuan Smash $\left(\mathbf{X}_{2}-\mathbf{Y}\right)$

\begin{tabular}{cccccc}
\hline & & $\mathrm{r}_{\text {tabel }}$ & & $\mathrm{t}_{\text {tabel }}$ & \\
$\mathrm{db}(\mathrm{N}-1)$ & $\mathrm{r}_{\text {hitung }}$ & $\square=0,05$ & thitung & $\square=0,05$ & Kesimpulan \\
\hline 19 & 0,5196 & 0,4560 & 2,5799 & 2,0930 & Signifikan \\
\hline
\end{tabular}

Hasil analisis korelasi menyatakan terdapat keberartian hubungan antara daya tahan kekuatan otot lengan dengan kemampuan Smash pada taraf signifikan $\alpha=0,05$.

\section{Penguji Hipotesis Tiga}

Pengujian hipotesis tiga yaitu terdapat hubungan antara daya tahan aerobik dan daya tahan kekuatan otot lengan dengan kemampuan Smash. Berdasarkan analisis dilakukan, maka diperoleh analisis korelasi antara daya tahan aerobik dan daya tahan kekuatan otot lengan terhadap kemampuan Smash.

Tabel 9. Analisis Korelasi antara Daya Tahan Aerobik dan Daya Tahan Kekuatan Otot Lengan terhadap Smash

\begin{tabular}{cccccc}
\multicolumn{8}{c}{$\left(\mathbf{X}_{1}, \mathbf{X}_{2}-\mathbf{Y}\right)$} \\
\hline $\mathrm{db}(\mathrm{N}-1)$ & $\mathrm{R}_{\text {hitung }}$ & $\begin{array}{c}\mathrm{R}_{\text {table }} \\
\square=0,05\end{array}$ & $\mathrm{~F}_{\text {hitung }}$ & $\begin{array}{c}\mathrm{F}_{\text {table }} \\
\square=0,05\end{array}$ & Kesimpulan \\
\hline 19 & 0,6948 & 0,4560 & 7,9336 & 3,5900 & Signifikan \\
\hline
\end{tabular}

Hasil analisis korelasi menyatakan terdapat hubungan yang berarti antara daya tahan aerobik dan daya tahan kekuatan otot lengan terhadap kemampuan Smash ada taraf signifikan a $=0,05$.

\section{Pembahasan}

\section{Daya Tahan Aerobik}

Merujuk pada hasil analisis penelitian yang membuktikan bahwa terdapat hubungan yang signifikan antara daya tahan aerobik dengan kemampuan Smash pemain bulutangkis Pasie Nan Tigo dengan koefesien korelasi $=0,4560$ pada $\alpha=$ $0,05 . \boldsymbol{r}_{x y}$ (koefisien korelasi) $=0,5622>\mathrm{r}_{\text {tab }}$ 0,4560. Artinya kemampuan Smash pemain dipengaruhi oleh daya tahan aerobik.

Tingkat daya tahan aerobik yang dimiliki pemain tentu akan lebih baik apabila tidak mengabaikan faktor-faktor yang dapat mempengaruhi kemampuan Smash.

\section{Daya Tahan Kekuatan Otot}

\section{Lengan}

Merujuk pada hasil analisis penelitian yang membuktikan bahwa terdapat hubungan yang signifikan antara daya tahan kekuatan otot lengan dengan kemampuan Smash pemain dengan koefesien korelasi $=0,4560$ pada $\alpha=0,05 . \boldsymbol{r}_{x y}$ (koefisien korelasi) $=$ 0,5196> $\mathrm{r}_{t a b}$ 0,4560. Artinya kemampuan Smash pemain dipengaruhi oleh daya tahan kekuatan otot lengan.

\section{SIMPULAN}

Peneliti akan menyampaikan kesimpulan dan pembahasan penelitian yang sudah dilakukan seperti: 1) Daya tahan aerobik memiliki hubungan yang signifikan dengan kemampuan Smash pemain bulutangkis 
Pasie Nan Tigo. , $\mathrm{r}_{\text {hitung }}(0,6545)>\mathrm{r}_{\text {tab }}$ $(0,4560), 2)$ Daya tahan kekuatan otot lenganmemiliki hubungan yang signifikan dengan kemampuan Smash pemain bulutangkis. $\left.\mathrm{r}_{\text {hitung }}(0,5196)>\mathrm{r}_{\mathrm{tab}}(0,4560), 3\right)$ Daya tahan aerobik dan daya tahan kekuatan otot lengan secara bersama-sama memiliki hubungan yang signifikan dengan kemampuan Smash pemain bulutangkis. Rhitung $(0,7279)>_{\text {Rtab }}(0,4560)$.

Selanjutnya kesimpulan di atas; Disarankan kepada para pelatih untuk dapat meningkatkan kemampuan Smash, makaperlu ditingkatkan latihan yang berkenaan dengan latihan selain latihan daya tahan aerobik dan daya tahan kekuatan otot lengan.

\section{DAFTAR PUSTAKA}

Asnaldi, A. (2016). Hubungan Pendekatan

Latihan Massed Practice Dan Distributed Practice Terhadap Ketepatan Pukulan Lob Pemain Bulutangkis. Jurnal MensSana. https://doi.org/https://doi.org/10.2403 6/jm.v1i2.51

Asnaldi, A. (2019). Kontribusi Motor Ability Dan Konsentrasi Terhadap Kemampuan Penguasaan Kata Heian Yodan Karateka Lemkari Dojo Angkasa Lanud Padang. Jurnal $\begin{array}{lrr}\text { Menssana, } & 4(1),\end{array}$ https://doi.org/10.24036/jm.v4i1.30

Asnaldi, A. (2020). Hubungan Kelentukan dan Daya Ledak Otot Lengan Terhadap Ketepatan Smash Bolavoli. Physical Activity Journal, 1(2), 160-
175.

https://doi.org/https://doi.org/10.3242 4/1.paju.2020.1.2.2556

Asnaldi, A., \& Kibadra, K. (2019). Sosialisasi Program Latihan Motor Ablity Kepada Asisten Pelatih Dojo Lembaga Karate-Do Indonesia SeKecamatan Koto Tangah. Jurnal Berkarya Pengabdian Masyarakat, l(1), 67-74. https://doi.org/10.24036/JBA.V1I1.3 3

Ella Anugrarista, A. (2019). Pengaruh Metode Latihan dan Koordinasi Matatangan Terhadap Keterampilan Smash Bulutangkis. Jurnal MensSana, 4(1), $1-8$.

https://doi.org/https://doi.org/10.2403 6/jm.v4i1.28

Erik Eriyaldi, M. (2019). Pengaruh Latihan Plyometric Menggunakan Metode Circuit Terhadap Kemampuan Smash Atlet Bolavoli | Jurnal Patriot. Jurnal Patriot, 2(5), 1160-1168. http://patriot.ppj.unp.ac.id/index.php/ patriot/article/view/375

Hardiansyah, S. (2018). Analisis Kemampuan Kondisi Fisik

Mahasiswa Fakultas Ilmu Keolahragaan Universitas Negeri Padang. Jurnal MensSana, 3(1), 117123.

https://doi.org/https://doi.org/10.2403 6/jm.v3i1.72

M, Edrizal, A. A. (2018). Hubungan Antara $\mathrm{VO}_{2} \max$ Dengan Hasil Belajar Siswa 
43| Arie Asnaldi ${ }^{1}$

Hubungan Daya Tahan Aerobik dan Daya Tahan Kekuatan Otot Lengan

Edrizal. Jurnal Sport Science, 18(1),

$10-20$.

https://doi.org/https://doi.org/10.2403

6/jss.v18i1.13

Rahmat Hidayat, U. (2019). Tingkat

Kondisi Fisik Atlet Bolavoli | Jurnal

Patriot. Jurnal Patriot, 1(2), 254-262.

http://patriot.ppj.unp.ac.id/index.php/

patriot/article/view/40

Rosmawati. (2016). Hubungan Daya Ledak

Otot Tungkai Dengan Kemampuan

Shooting Pemain Club Futsal Sekolah

Menengah Kejuruan Nusatama

Padang. Jurnal MensSana, 1(2), 11-

19.

https://doi.org/https://doi.org/10.2403

6/jm.v1i2.49

Sepriani, R., Rosmaneli, R., \& Asnaldi, A. (2018). Efektivitas Minuman Energi Terhadap Daya Tahan Aerobik.

Sporta Saintika, 1(2), 175-188. https://doi.org/10.24036/sporta.v1i2.4 0

Suwirman, S. (2019). Peningkatan Kualitas

Pelatih Pencak Silat Di Kabupaten

Dharmasraya. Jurnal Berkarya

Pengabdian Masyarakat, 1(1), 1-12. https://doi.org/10.24036/JBA.V1I1.1

Zil Isra, A. A. (2020). Analisis Koordinasi

Teknik Jump Smash Pemain

Bulutangkis PB. Formula Padang

Panjang | Isra | Jurnal Kepelatihan

Olahraga. Jurnal Kepelatihan

Olahraga, 12(1), 45-55.

https://ejournal.upi.edu/index.php/JK

O/article/view/24013/11680 